\title{
Evidence for a relationship between cage stereotypies and behavioural disinhibition in laboratory rodents
}

\author{
Joseph P. Garner ${ }^{\mathrm{a}, *}$, Georgia J. Mason ${ }^{\mathrm{b}}$ \\ ${ }^{a}$ Department of Animal Science, University of California, One Shields Avenue, Davis, CA 95616, USA \\ ${ }^{\mathrm{b}}$ Department of Zoology, Oxford University, South Parks Road, Oxford OX1 3PS, UK
}

Received 15 January 2002; received in revised form 8 April 2002; accepted 8 April 2002

\begin{abstract}
Cage stereotypies - abnormal, repetitive, unvarying and apparently functionless behaviours — are common in many captive animals, sometimes resulting in self-injury or decreased reproductive success. However, a general mechanistic or neurophysiological understanding of cage stereotypies has proved elusive. In contrast, stereotypies in human mental disorder, or those induced by drugs or brain lesions, are well understood, and are thought to result from the disinhibition of behavioural selection by the basal ganglia. In this study, we found that the cage stereotypies of captive bank voles also correlate with signs of altered response selection by the basal ganglia. Stereotypic bar-mouthing in the caged voles correlated with inappropriate responding in extinction learning, impairments of response timing, evidence of a knowledge-action dissociation, increased rates of behavioural activation, and hyperactivity. Furthermore, all these signs intercorrelated, implicating a single underlying deficit consistent with striatal disinhibition of response selection. Bar-mouthing thus appears fundamentally similar to the stereotypies of autists, schizophrenics, and subjects treated with amphetamine or basal ganglial lesions. These results represent the first evidence for a neural substrate of cage stereotypy. They also suggest that stereotypic animals may experience novel forms of psychological distress, and that stereotypy might well represent a potential confound in many behavioural experiments. (C) 2002 Elsevier Science B.V. All rights reserved.
\end{abstract}

Keywords: Stereotypy; Abnormal behaviour; Schizophrenia; Autism; Animal welfare; Basal ganglia; Bar mouthing; Executive functioning; Striatal dysfunction

\section{Introduction}

Stereotypies are repetitive sequences of motor behaviour that are topographically and morphologically invariant, often rhythmical, and apparently purposeless (e.g. $[8,18,45,58])$. They are commonly displayed by zoo, farm and laboratory animals. For example, stereotypies like bar-mouthing are widespread in rodents caged as research models, including laboratory mice [50,77], chinchillas [34], black rats [11], deer mice [58], field voles [21], and bank voles [12,14,21]. They are also sometimes extremely prevalent (present in ca. $98 \%$ of male ICR mice: [77]). Such 'cage stereotypies' are typically elicited by the frustration of specific motivated behaviours (e.g. $[49,62,70])$, in combination with stress

\footnotetext{
* Corresponding author. Tel.: +1-530-752-1253; fax: +1-530-7520175

E-mail address: jpgarner@ucdavis.edu (J.P. Garner).
}

(e.g. $[9,75])$ and a reduction in behavioural competition caused by low environmental complexity (e.g. $[29,66])$. However, although the causation of particular cage stereotypies is fairly well understood at the motivational level (e.g. [70,77]), a more general neurophysiological understanding of these behaviours is lacking. Thus while dopaminergic and opiate receptor antagonists (e.g. [33]), and a variety of serotonergic agents [35,57], are all known to suppress cage stereotypy, evidence for baseline alterations in neurotransmitter function is inconsistent (e.g. $[54,58])$. This may indicate that multiple neurotransmitter systems are involved, just as they are in drug-induced stereotypy (for review see: $[9,25,28,65]$ ), or that, rather than the transmitter levels and receptor densities most commonly measured (e.g. [54,58]), subtle aspects of the systems are implicated such as receptor sensitivity (e.g. [6,58]).

This lack of a consistent neurophysiological understanding of cage stereotypies is in marked contrast with 
other forms of stereotypy (for review see [25]). All clinical, drug- and lesion-induced stereotypies for which a neural substrate is known, involve altered function in the dorsal striatum that causes reduced behavioural inhibition. For instance, dopamine $\mathrm{D}_{2}$ receptor agonists such as amphetamine induce a general disinhibition of behaviour that culminates in stereotypy $[9,40,68]$. Stereotypies induced by amphetamine are mediated by their action in the dorsal basal ganglia (e.g. [32]). Similarly, isolation-rearing induces both stereotypy and changes in basal ganglia dopaminergic tone $[36,37,42]$, as does premature weaning [24,63]. Basal ganglia lesions in humans are similarly associated with stereotypy-like behaviour [1,39]. Stereotypy is also a common sign in disorders such as autism and schizophrenia [23,56,67]. In autism [67] and schizophrenia [23], the severity of stereotypy correlates with impairments on tasks designed to detect the unique signs of dorsal basal ganglia dysfunction. Stereotypies also correlate with the inappropriate repetition of words in schizophrenic speech [41]; and in schizophrenia other 'disorganised symptoms' (e.g. unpredictable agitation, 'derailment', 'tangentiality' in thought and speech, and disinhibited or fragmented behaviour: [4]) may be related to the disinhibition of responses characteristic of dorsal basal ganglia dysfunction [17]. In all of these examples, the precise cellular mechanisms vary, but the systems-level dysfunction causing stereotypy is essentially the same $[1,25,28,65,67,69]$.

The ubiquitous association of stereotypy with dorsal basal ganglia dysfunction is consistent with the essential role this structure plays in the motor system (c.f. $[1,52,66])$. Thus the selection and sequencing of normal behaviour and movement is regulated by the interaction of two agonistic cortico-striatal circuit loops, running through the dorsal basal ganglia $[1,3,60]$. The first, 'direct', pathway activates motor programs, whilst the second, 'indirect', pathway is inhibitory, acting to allow the proper transition between competing programs. Each pathway is regulated by different neurotransmitters or receptor subtypes. Thus dopamine $\mathrm{D}_{1}$ receptors are concentrated in the direct pathway, whilst dopamine $\mathrm{D}_{2}$ receptors are concentrated in the indirect pathway; and within-circuit negative feedback is provided by dynorphin releasing neurones in the direct pathway, and enkephalin releasing neurones in the indirect pathway (for review see: $[2,25,28,65])$. Thus lesions or drugs affecting the direct pathway (e.g. agents acting selectively at the dopamine $D_{1}$ receptor) lead to a general activation or suppression of all behaviour $[1,68]$, while lesions or drugs affecting the indirect pathway (e.g. agents acting selectively at the dopamine $\mathrm{D}_{2}$ receptor, or opiate agonists acting on receptors sensitive to enkephalin) selectively induce or suppress stereotypy $[1,38,68]$. Overall, the vast variety of drugs that can induce stereotypy, therefore, do so via suppressing indirect pathway activity, often (though not always: see [19]) by influencing its dopaminergic regulation.

If drug- and lesion-induced stereotypies seem to involve a systems-level disinhibition of behaviour, via the suppression of the inhibitory influence of the indirect pathway, could this also account for cage stereotypies? A similar dysfunction in cage stereotypy would have important ethical and animal welfare implications (e.g. [5]), as well as implications for the use of laboratory rodents as valid research models (e.g. [72,73]). Furthermore, four features of cage stereotypy do suggest that the behaviour may reflect impaired function. First, the long-term effects of abnormal rearing conditions on cage stereotypy suggest that the behaviour may reflect altered CNS development. For example, in bank voles and black rats, stereotypies do not appear in caged animals wild-caught as adults, only in laboratory-reared subjects [11,12]; and in mice and mink, they are most prevalent in early-weaned animals [43,76]. Second, several observations suggest an underlying change in behavioural organisation: as stereotypies develop, they become increasingly hard to abolish with opioid antagonists [33] and environmental enrichment [14,47]; and stereotypic animals also sometimes show reduced behavioural responsiveness to external stimuli (e.g. $[13,71])$. Third, stereotypies can cause reduced physical health to the performer or its offspring. For example, cage stereotypies may result in self-injury in many species (e.g. [53]), or deficits in maternal behaviour that impair the growth (e.g. [46]) or increase the mortality (e.g. [64]) of offspring. Fourth, treatments which enhance the development of cage stereotypies [45] also induce widespread changes in the brain, and a general disinhibition of behavioural responses in rodents [48,61]. Taken together, these studies argue for a role of dysfunctional behavioural organisation in cage stereotypy. However, to date, quantitative investigation of this possibility has been lacking.

We therefore investigated the role of basal ganglia dysfunction in rodent cage stereotypy, by measuring the behavioural correlates of bar-mouthing. Since they stem from decreased behavioural inhibition, stereotypies caused by clinical or experimentally-induced basal ganglia dysfunction form part of a suite of changes in behaviour. These include enhanced rates of behavioural initiation [20,40]; 'impulsivity' [59]; impaired performance in tasks where responses must be suppressed or slowed [20,40,59]; the inappropriate repetition, or 'perseveration' of previous actions [20,39], which impairs performance in tasks such as extinction learning $[23,31,48,67]$; and a concurrent knowledge-action dissociation in such tasks, whereby human subjects know (and report) the correct response to make but are unable to suppress automatic repetition of a previous, incorrect response [67]. Thus along with stereotypies, isolationreared primates show poor abilities to suppress inap- 
propriate behaviour in extinction [7,27], while the stereotypy frequencies of human subjects with autism and schizophrenia correlate with their inappropriate repetition of responses in gambling or sequence-generation tasks $[23,67]$. If rodent cage stereotypies are similarly indicative of altered central functioning, then they too should correlate with similar signs of impaired behavioural inhibition. We tested this hypothesis using bank voles, a convenient murid model of cage stereotypy $[12,33]$.

\section{Materials and methods}

\subsection{Subjects}

Eight laboratory-bred bank voles (Clethrionomys glareolus) were singly housed from weaning at 21 days of age in opaque plastic mouse cages $(32 \times 20 \times 19 \mathrm{~cm})$ with sawdust bedding and ad libitum pellets and water, on a 14-h light:10-h dark cycle. Animal housing, care, and use was in accordance with UK Home Office, and institutional (Zoology Department, Oxford University, UK) guidelines.

\subsection{Video observations}

Bank voles are active throughout the 24-h day in a series of activity cycles lasting approximately $4 \mathrm{~h}$ [53]. This feature of their behaviour makes them particularly suitable subjects for behavioural work. Thus continuous video was recorded from 10:00 to 18:00 h (i.e. during lights-on), to ensure capturing at least one activity cycle. The first $4 \mathrm{~h}$ of activity (i.e. all non-sleep behaviour) on the tape were observed, and stereotypy recorded using a one-zero method with $30 \mathrm{~s}$ intervals, to find the proportion of total activity spent stereotyping. All animals performed a 'bar mouthing' stereotypy, where the animal held the cage bar in the diastema, and made a series of sham biting movements along the bar. These biting movements are idiosyncratic and conserved within individuals, both in their form, and in the cage location where they are performed $[25,50,51,77]$.

\subsection{General analytical methods}

General Linear Models (GLM) were employed throughout. Suitable transformations were applied where necessary to meet the assumptions of parametric methods (normality of error, homogeneity of variance, and linearity). Further details are provided for each experiment below. All tests are one-tailed because in all cases the sign of the correlation was predicted, and the opposite sign would falsify our hypothesis.

\subsection{Rate of behaviour initiation}

In amphetamine-induced stereotypies, stereotypy is the endpoint of a process in which the inhibition of competing behavioural responses is reduced and lost, and the switching between behaviours becomes so rapid that only the most predominate behaviours can be initiated, until a single behavioural element is being continuously repeated. Thus as stereotypy emerges, the rate at which individuals switch between behaviours increases [40]. If cage stereotypy involves a similar mechanism, then the amount of stereotypy performed by an individual should correlate with the rate at which it switches between all behaviours.

The ethogram of behaviours in the bank vole is described in [25]. For each animal, four periods, each of $4 \mathrm{~min}$ continuous activity, were chosen at random from the $8 \mathrm{~h}$ of continuous video described previously. To ensure that the analysis compared like-with-like for low and high stereotypy animals, two 4-min periods when stereotypy was performed, and two when no stereotypy was performed were selected for each animal (using the one-zero data recorded previously). Thus independent of the overall stereotypy score of the animal, the videos selected for intensive observation were as similar as possible in terms of stereotypy. Stereotypy was included as a behaviour to switch between; this ensured a conservative test of the hypothesis because if stereotypy is a confound due to the 'blocking' of other activities, then it will reduce rather than inflate the magnitude of the relationship predicted.

The total 16 min for each animal were observed using continuous recording. Each time a bout of behaviour was initiated was counted as one initiation, regardless of the previous behaviour, for instance the sequence 'Feeding-Drinking-Drinking-Locomotion-

Grooming-Nestbuilding' contains five initiations, as the vole paused between the two drinking bouts. However, in order to compare like with like, initiations of sub-elements within a behaviour chain were not counted (e.g. transitions between individual grooming movements were not counted). The mean number of behaviours initiated per minute was calculated, and correlated with stereotypy. The analysis was partialled for sex.

\subsection{Maze tasks}

Damage to the dorsal basal ganglia leads to a general tendency to inappropriately repeat previous responses, called recurrent perseveration [39,52,67]. Recurrent perseveration, as measured on a number of tasks, is also correlated with stereotypy in both schizophrenic [23] and autistic [67] patients. We therefore predicted that cage stereotypy would correlate with a general tendency to repeat previous responses. We measured 
this tendency by examining the ability of each subject to suppress a previously learnt response in a spatial extinction task (c.f. [31]).

The maze was constructed from transparent plastic tubing, and was mounted on the home cage. The homecage was moved to a separate room for testing. The tasks were run automatically by computer, which collected all data, and dispensed rewards as appropriate. The tasks were run over consecutive sessions, each lasting between 20 and 40 trials. Upon entering the maze from the home cage, subjects chose between one of two corridors. Each corridor contained a glass nozzle that could deliver $0.015 \mathrm{ml} \mathrm{10 \%} \mathrm{w/v} \mathrm{sucrose} \mathrm{solution}$ reward. One-way doors prevented the vole from backtracking on itself. Each corridor exited via a one-way door back into the home cage. Infrared photobeams monitored the position of the animal in the maze (Fig. 1). Voles were food deprived for $6 \mathrm{~h}$ before testing. In the spatial discrimination task one corridor was rewarded (chosen at random for each animal at the start of the experiment, and balanced within sex). The criterion for completion of spatial discrimination was set at choosing 18/20 correct over three consecutive trials.

Once criterion was attained, extinction learning was assessed. In the extinction task, neither location provided reward. Criterion was now choosing at chance (13/ 20 or less for three consecutive trials). The number of trials to complete the extinction tasks was then correlated with stereotypy; this analysis was partialled for (i.e. statistically controlled for) sex and the number of trials taken to learn the spatial discrimination. Spatial discrimination and extinction learning involve a variety of common psychological processes. However, the key difference between these tasks is the inhibition of the response in extinction learning - a process known to involve the basal ganglia. Therefore, including spatial discrimination performance in the analysis allows each vole to act as its own control, explicitly removing the effect of common processes (e.g. motivational, perceptual, hedonic, or associative) and providing a pure measure of the unique feature of extinction-namely the inhibition of responses.

When rats learn a simple discrimination they make correct choices rapidly, but make incorrect choices after a longer latency [55]; amphetamine treated animals, however, fail to suppress rapid responding when it is made inappropriate [59]. We therefore used response latencies in extinction to see how readily our subjects suppressed rapid responding in the previously correct side of the maze. We predicted that stereotypy would be correlated with an impairment in the suppression of rapid responding. 'Latency to choose' equals the time between crossing the photobeam at the maze entrance, and the photobeam at the entrance of the chosen corridor. The mean latency to choose the incorrect side of the maze over the previous 20 trials was divided by the mean latency to choose the correct side of the maze, $(R)$. The criterion for divergence of choice latencies during learning was defined as $R>2.0$ for three trials, and the criterion for convergence of latencies in extinction was defined as $R<1.1$ for three trials. Stereotypy was correlated with the number of trials taken to show convergence of choice latencies in extinction. The analysis was partialled for sex and the number of trials taken to show a divergence of choice latencies during spatial discrimination (to control for motivational, perceptual and learning differences).

These data were then used to investigate evidence of a knowledge-action dissociation. Stereotypic human patients, and those with basal ganglia pathology, show a discrepancy between two behavioural signs of knowledge: verbal reports, and performance in knowledgedependent tasks $[39,67]$. Our subjects similarly demonstrated two behavioural signs of knowledge: the nature and the latencies of their choices. In extinction, knowledge of the task is demonstrated both as choices return to chance, and as the latency to choose the previously correct side increases to match that of the previously incorrect side. The dissociation between these two behavioural signs of knowledge was therefore quantified by the magnitude of this latency increase at the point where the animal had successfully reverted to choosing at chance (see Fig. 2). We therefore predicted that the magnitude of the increase in the latency to choose the previously rewarded side of the maze would be negatively correlated with stereotypy. This analysis was partialled for sex, and the increase in the previously

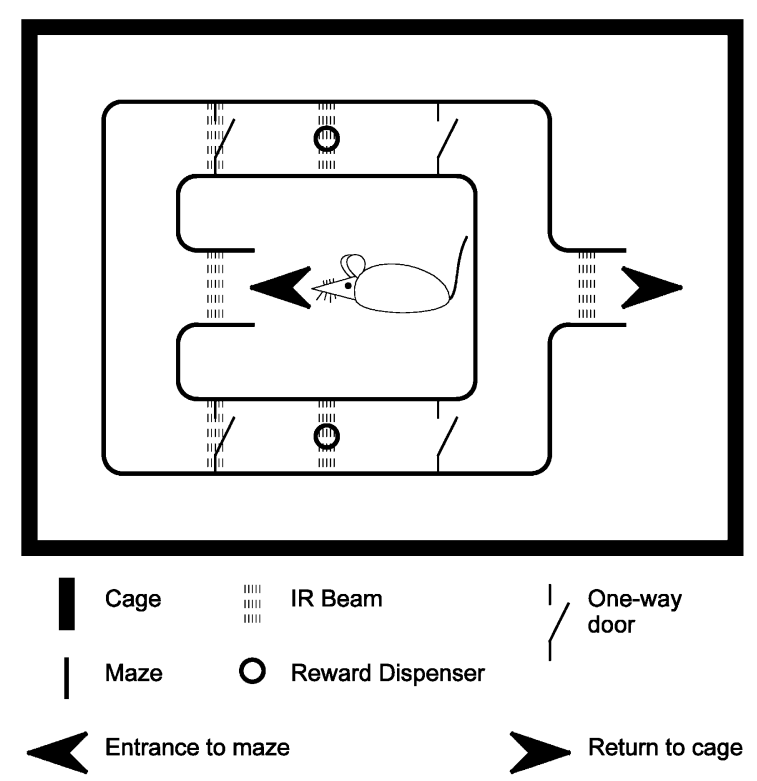

Fig. 1. The maze apparatus (see text for a detailed description). The maze was mounted on top of the home cage. The apparatus was monitored and controlled by computer. Thus multiple trials could be run without the experimenter interacting with the vole. 
-. - Proportion of choices correct

- - - Latency of previously correct choices

Latency of previously incorrect choices

(a)

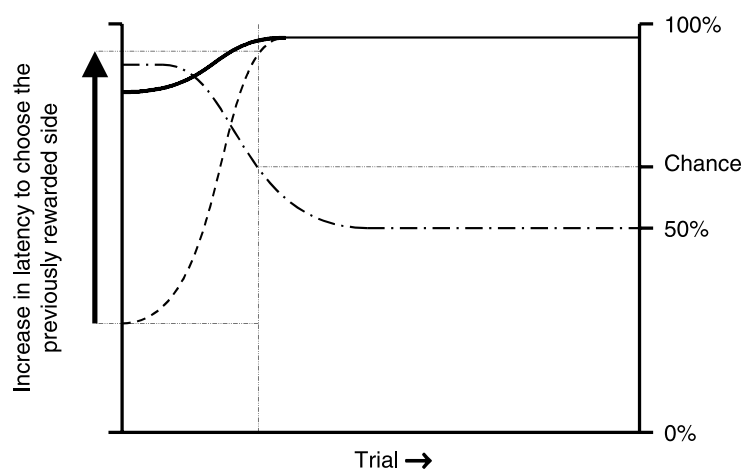

(b)

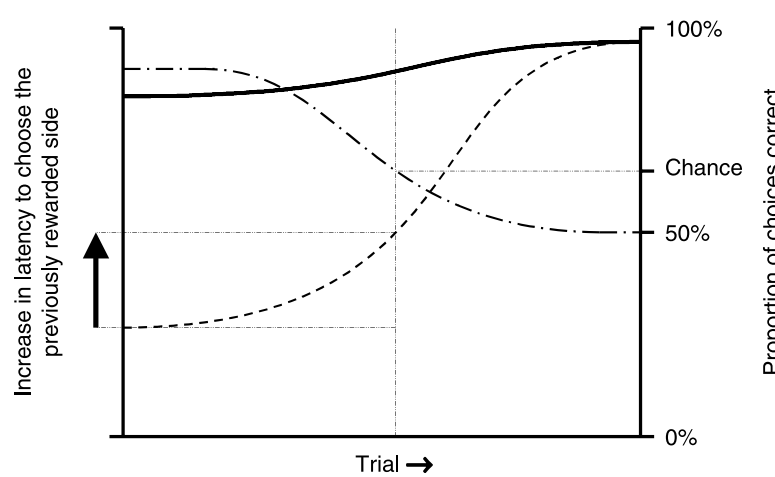

Fig. 2. The theory behind demonstrating a knowledge-action dissociation in extinction. The solid line represents the latency to choose the previously unrewarded side of the maze, the dashed line the latency to choose the previously rewarded side, and the dot-dashed line the current score. In both figures the point where the animal reaches criterion on choices (i.e. is responding statistically at chance, and so must 'know' that it will not be rewarded) is indicated, and the increase in latency to choose the previously rewarded side of the maze is taken directly from the curve. (a) depicts an animal showing a large increase in latency at this point, thereby expressing knowledge of the absence of reward in latencies. (b) depicts an animal showing a small increase in latency to choose the previously rewarded side of the maze. Thus, despite showing that it understands that it will not be rewarded by its choices, the animal appears not to 'know' that it will not be rewarded when the latencies of these choices are examined. Thus the increase in this latency at the point where each animal is choosing the two sides of the maze at chance, directly measures the dissociation between the knowledge expressed in these two measures. Low stereotypy animals are predicted to show agreement (a), whilst high stereotypy animals are predicted to show dissociation (b).

incorrect choice latency. This latter covariate controls for individual differences (for instance in motivation), and the fact that latencies to choose tend to increase for both sides of the maze during extinction.

\subsection{Home cage activity}

Infrared beams were placed across the drinker and the cage lid, away from locations or routes associated with the stereotypies. The total number of beam breaks between 17:00 and 10:00 $\mathrm{h}$ was recorded, and the mean number of beam breaks per minute calculated. Stereotypy was square-transformed to correct nonhomogeneity of variance. The analysis was partialled by sex.

\section{Results}

\subsection{Stereotypy}

Individuals differed in the proportion of active behaviour spent in stereotypy, ranging from 3.5 to $28.1 \%$. The most stereotypic animals also occasionally displayed a high-frequency tremor of the limbs when climbing the cage lid.

\subsection{Rate of behaviour initiation}

To test the prediction that stereotypy correlates with a generally increased rate of initiation of all behaviour, we analysed homecage behaviour. As predicted, the mean rate of behaviour initiation was positively correlated with stereotypy (GLM: $F_{1,5}=19.38 ; P=0.0035$ ) (Fig. $3)$.

\subsection{Maze tasks}

The number of trials to acquire the spatial discrimination (SD) was uncorrelated with stereotypy. However, as predicted, stereotypy was positively correlated with the number of trials taken to complete the extinction task (GLM, partialled for sex and SD: $F_{1,4}=77.29 ; P=$ 0.0005) (Fig. 4). Whilst the least stereotypic animal extinguished in 26 trials, the most stereotypic animal took 244 .

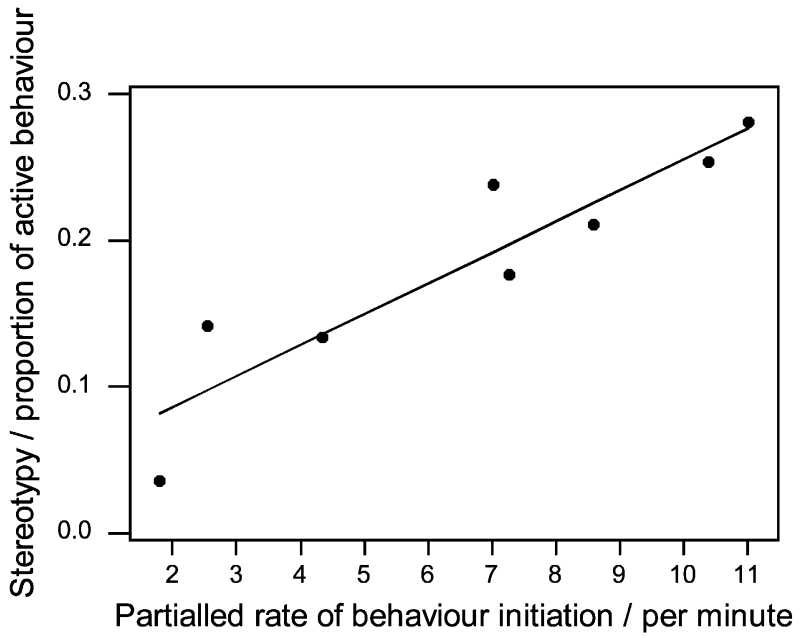

Fig. 3. Stereotypy is positively correlated with the spontaneous rate of initiation of all behaviours in the homecage (GLM; $F_{1,5}=19.38 ; P=$ $0.0035)$. The $x$-axis is partialled for sex 


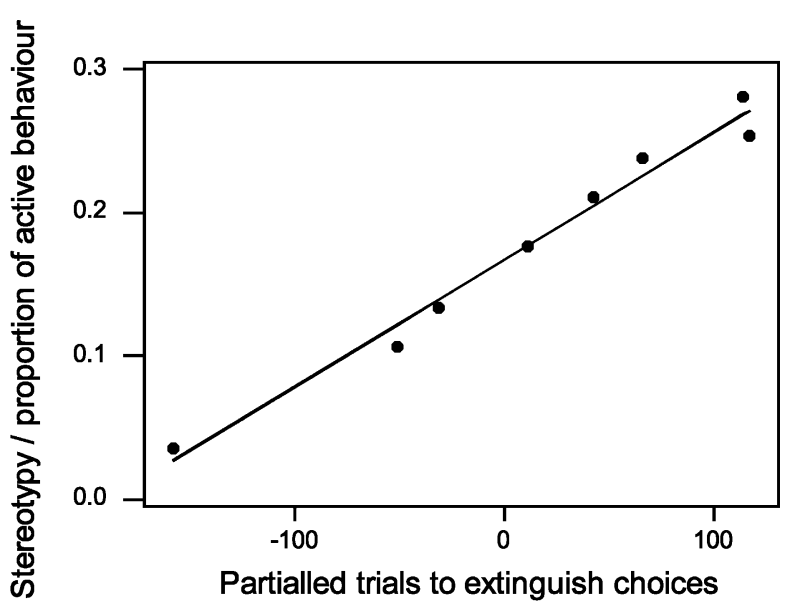

Fig. 4. Stereotypy correlates with a tendency to repeat previous responses (GLM: $\left.F_{1,4}=77.29 ; P=0.0005\right)$. The $x$-axis shows the number of trials taken to extinguish the previously learnt response, partialled for the number of trials taken to learn the original response (thereby controlling for motivational, perceptual or general learning differences), and sex.

During acquisition, correct choices were made faster than incorrect, while during extinction, animals reverted to choosing both arms of the maze with equal latencies. As predicted, stereotypy correlated with the number of trials taken to demonstrate equal choice latencies in both arms (GLM: $F_{1,4}=14.48 ; P=0.0095$ ), showing that in extinction, stereotypic animals persisted in responding rapidly to the previously-rewarded arm (Fig. 5).

As predicted, at the point where each vole was demonstrating complete knowledge by choosing both sides at chance, the most stereotypic animals displayed the smallest increases in their latencies to choose the previously rewarded side (GLM: $F_{1,4}=42.91 ; \quad P=$

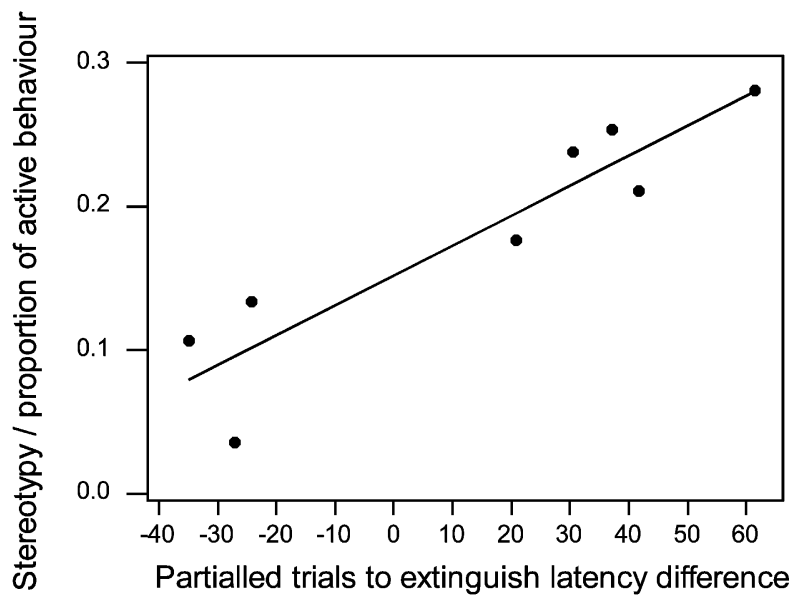

Fig. 5. Stereotypy is correlated with a tendency to persist in responding rapidly to the previously rewarded side of the maze (GLM: $F_{1,4}=$ 14.48; $P=0.0095)$. The $x$-axis shows the number of trials taken to choose both sides of the maze with an equal latency, corrected for sex and the number of trials taken to choose the correct side of the maze with a shorter latency during initial acquisition.

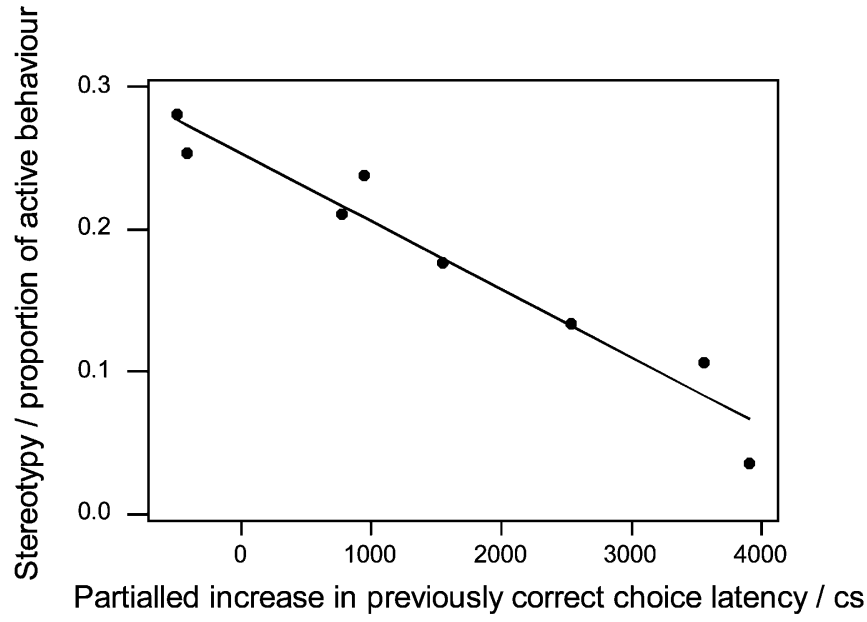

Fig. 6. Stereotypy correlates with evidence of knowledge-action dissociation (GLM: $F_{1,4}=42.91 ; P=0.0015$ ). In extinction, high stereotypy animals show a smaller increase in their latency to choose the previously rewarded side of the maze (i.e. their apparent knowledge) at the point where they are choosing at chance (i.e. showing by their choices that they 'understand' the task). The $x$-axis is partialled for sex, and the increase in latency to choose the previously unrewarded side of the maze (to control for individual differences, and changes in motivation).

0.0015) (Fig. 6), thus demonstrating the greatest discrepancies between their two behavioural signs of knowledge.

\subsection{Activity}

Unfortunately, one male and one female died prior to this final experiment. Nevertheless, as predicted, home cage activity levels were positively correlated with stereotypy (GLM: $\left.F_{1,3}=12.25 ; P=0.0195\right)$.

\subsection{Intercorrelation of measures}

The final, acid test of our hypothesis is whether all these measures inter-correlate. As predicted, all were positively correlated (Table 1). Indeed factor analysis of these data was not possible as all measures were so strongly correlated, implying that all these measures share a single common mechanism.

\section{Discussion}

To date, the understanding of clinical and experimentally-induced stereotypies has been little used to inform research on cage stereotypies $[25,58]$. Our study is thus the first to show a fundamental similarity between cage stereotypies and behaviours arising from basal ganglia dysfunction. As predicted, the bar-mouthing of caged voles correlated with the perseveration of response choices and short response latencies in extinction; 
Table 1

Intercorrelation of the signs of altered basal ganglia function in bank voles

\begin{tabular}{|c|c|c|c|c|c|}
\hline & Activity & Rate of initiation & Repetition of choices & $\begin{array}{l}\text { Repetition of } \\
\text { latencies }\end{array}$ & $\begin{array}{l}\text { Knowledge-action } \\
\text { dissociation }\end{array}$ \\
\hline Stereotypy & $r=0.857(P=0.0195)$ & $r=0.840(P=0.0035)$ & $r=0.642(P=0.0005)$ & $r=0.751(P=0.0095)$ & $r=0.790(P=0.0015)$ \\
\hline Activity & & $r=0.871(P=0.020)$ & $r=0.791(P=0.030)$ & $r=0.878(P=0.007)$ & $r=0.883(P=0.020)$ \\
\hline Rate of initiation & & & $r=0.556(P=0.015)$ & $r=0.840(P=0.008)$ & $r=0.926(P=0.0005)$ \\
\hline Repetition of choices & & & & $r=0.772(P=0.0145)$ & $r=0.830(P=0.0105)$ \\
\hline Repetition of latencies & & & & & $r=0.820(P=0.017)$ \\
\hline
\end{tabular}

Correlation coefficients $(r)$ between each combination of measures, and their significance $(P)$, are listed. Correlation coefficients are partialled for sex and other covariates where specified in the methods.

evidence of a knowledge-action dissociation; enhanced rates of initiation of all behaviours; and greater baseline activity levels. Furthermore, all these signs were tightly intercorrelated, implicating a single underlying deficit consistent with a striatal disinhibition of response selection.

The profound differences seen between high and low stereotypy animals in this study (e.g. an order of magnitude difference in extinction performance and rates of behavioural switching), together with the fact that environmental treatments which affect cage stereotypy [45] also impact brain development, extinction learning, and the disinhibition of responses [48,61], argue that the suite of intercorrelated signs reported here reflects a differential impact of the captive environment upon these animals.

Previous accounts of rodent bar-mouthing, focussing on its motivational basis, have shown that it derives from attempts to escape the cage $[49,77]$. By showing that it is part of a suite of signs of altered behavioural control, our results now account for the persistence of this escape-behaviour. They also raise the possibility that central deficits are involved in many of the cage stereotypies so common in laboratory, zoo and agricultural animals. This finding has both ethical and practical implications.

Cage stereotypies are generally considered an animal welfare issue [44,58]. Such ethical concerns will be increased by this evidence suggesting that caging causes striatal dysfunction. Furthermore, our evidence of knowledge-action dissociation raises the possibility that stereotypic animals, like some human clinical patients $[39,67]$, might feel frustrated by their impaired ability to turn decisions and preferences into actions.

Cage stereotypies could also potentially have some research value. Powell et al. [58] suggest that a mouse model of spontaneous stereotypy would be valuable for investigating the neural mechanisms of human clinical stereotypies, and our results support this suggestion. Our results also parallel other peculiar phenomena associated with stereotypy in clinical populations; for instance, the enhanced rates of switching between behaviours seen in high stereotypy animals may parallel the disorganisation syndrome of schizophrenia, lending support to the hypothesis that disorganised symptoms may reflect striatal disinhibition in these patients [17]. Our results also resemble findings that in institutionalised Down's Syndrome patients, stereotypies are linked with an increased frequency of other behaviours [22], and the importance of physical or social environments for the development of cage stereotypy could thus perhaps help us understand the potentially deleterious effects of institutionalisation. For instance, ethological techniques have been useful in identifying physical and social features which elicit stereotypy in autistic children [30]. However, and perhaps more importantly, our results also raise questions about the way caged rodents are currently used in research.

Rodent models are essential research tools for neurobiology and the pharmacology and genetics of behaviour (e.g. [16]), but as reviewed in the Section 1, such rodents commonly display stereotypies in standard laboratory conditions. If stereotypers are dysfunctional, this has obvious implications for external validity [72,73]: it suggests that rodents with stereotypies are unlikely to be good models of normal functioning, or to provide normal backgrounds (reviewed in: [26]) for genetic or pharmacological manipulations. Furthermore, the frequency of cage stereotypy differs greatly between individuals, between sites, and between mouse strains; and the magnitude of strain differences in stereotypy also varies with husbandry (see $[10,50,75]$ ). Thus cage stereotypies represent an enormously variable, and currently uncontrolled - for, potential confound. This may well account for some strain and site effects on research results. For example, the behavioural disinhibition of stereotypers is particularly likely to affect any behaviour-based test involving locomotor activity, Open Field behaviour, reactivity to novelty, or extinction/ reversal learning. Laboratory differences in cage stereotypy may therefore help predict and explain laboratory 
differences in the results of standard behavioural tests [15].

Overall, we therefore suggest that husbandry techniques promoting low cage stereotypy-such as later weaning, [75], and suitable environmental enrichments $[14,50,58,74]$ — will enhance the validity and replicability of laboratory rodent behavioural data, as well as improving caged rodents' welfare.

\section{Acknowledgements}

J.P. Garner was supported by a BBSRC studentship, G.J. Mason by a BBSRC David Phillips fellowship. This paper benefited from discussion with Jonathan Cooper, Robert Dantzer, Marian Dawkins, Rob Deacon, Robin McCleery, Joy Mench, Nick Rawlins, Trevor Robbins, Michelle Turner, and Hanno Würbel. Judith Lloyd, Tony Price and Phil Taylor provided invaluable technical assistance.

\section{References}

[1] Albin RL, Young AB, Penney JB. The functional anatomy of basal ganglia disorders. Trends Neurosci 1989;12:366-75.

[2] Alexander GE, Crutcher MD. Functional architecture of basal ganglia circuits - neural substrates of parallel processing. Trends Neurosci 1990;13:266-71.

[3] Alexander GE, Crutcher MD, DeLong MR. Basal gangliathalmocortical circuits: parallel substrates for motor, oculomotor, 'prefrontal' and 'limbic' functions. Prog Brain Res 1990;85:11946.

[4] American Psychiatric Association, Diagnostic and statistical manual of mental disorders (4th ed.). Washington, DC, USA: American Psychiatric Association, 1994, xxvii, p. 886.

[5] Appleby MC, Hughes BO, Animal Welfare, Wallingford, Oxon, UK; New York: CAB International, 1997:316.

[6] Bardo MT, Valone JM, Robinet PM, Shaw WB, Dwoskin LP. Environmental enrichment enhances the stimulant effect of intravenous amphetamine: search for a cellular mechanism in the nucleus accumbens. Psychobiology 1999;27:292-9.

[7] Beauchamp AJ, Gluck JP. Associative processes in differentially reared monkeys (Macaca mulatta): sensory preconditioning. Dev Psychobiol 1988;21:355-64.

[8] Berkson G. Development of abnormal stereotyped behaviours. Dev Psychobiol 1968;1:118-32.

[9] Cabib S. Neurobiological basis of stereotypies. In: Lawrence AB, Rushen J, editors. Stereotypic animal behaviour: fundamentals and applications to welfare. Wallingford, England, UK; Tucson, Arizona, USA: CAB International, 1993:119-45.

[10] Cabib S, Bonaventura N. Parallel strain-dependent susceptibility to environmentally-induced stereotypies and stress-induced behavioural sensitisation in mice. Physiol Behav 1997;61:499-506.

[11] Callard MD, Bursten SN, Price EO. Repetitive backflipping behaviour in captive roof rats (Rattus rattus) and the effects of cage enrichment. Anim Welfare 2000;9:139-52.

[12] Cooper JJ, Nicol CJ. Stereotypic behaviour in wild caught and laboratory bred bank voles (Clethrionomys glareolus). Anim Welfare 1996;5:245-57.
[13] Cooper J-J, Nicol C-J. Stereotypic behaviour affects environmental preference in bank voles Clethrionomys Glareolus. Anim Behav 1991;41:971-7.

[14] Cooper JJ, Ödberg F, Nicol CJ. Limitations on the effectiveness of environmental improvement in reducing stereotypic behaviour in bank voles (Clethrionomys glareolus). Appl Anim Behav Sci 1996;48:237-48.

[15] Crabbe JC, Wahlsten D, Dudek BC. Genetics of mouse behaviour: interactions with laboratory environment. Science 1999;284:1670-2.

[16] Crawley JN, What's wrong with my mouse? Behavioural phenotyping of transgenic and knockout mice. New York: Wiley-Liss, 2000:329.

[17] Crider A. Perseveration in schizophrenia. Schizophr Bull 1997;23:63-74.

[18] Dantzer R. Behavioural, physiological and functional aspects of stereotypic behaviour: a review and reinterpretation. J Anim Sci 1986;62:1776-86.

[19] Eberle-Wang K, Lucki I, Chesselet MF. A role for the subthalamic nucleus in 5-HT2C-induced oral dyskinesia. Neuroscience 1996;72:117-28.

[20] Evenden JL, Robbins TW. Increased response switching, perseveration and perseverative switching following d-amphetamine in the rat. Psychopharmacology 1983;80:67-73.

[21] Fentress JC. Dynamic boundaries of patterned behaviour: interaction and self-organisation. In: Bateson PPG, Hinde RA, editors. Perspectives in ethology, vol. 1. New York: Plenum Press, 1976:155-224.

[22] Francis S. An ethological study of mentally retarded individuals and normal individuals. University of Cambridge, 1966.

[23] Frith CD, Done DJ. Stereotyped responding by schizophrenicpatients on a 2-choice guessing task. Psychol Med 1983;13:77986

[24] Fry JP, Sharman DF, Stephens DB. Cerebral dopamine, apomorphine and oral activity in the neonatal pig. J Vet Pharmacol Ther 1981;4:193-207.

[25] Garner JP. The aetiology of stereotypy in caged animals. Oxford: University of Oxford, 1999.

[26] Gerlai R. Gene-targeting studies of mammalian behaviour - is it the mutation or the background genotype. Trends Neurosci 1996;19:177-81.

[27] Gluck JP, Sackett GP. Extinction deficits in socially isolated rhesus monkeys (Macaca mulatta). Dev Psychol 1976;12:173-4.

[28] Hauber W. Involvement of basal ganglia transmitter systems in movement initiation. Prog Neurobiol 1998;56:507-40.

[29] Hughes BO, Duncan IJ. The notion of ethological 'need', models of motivation and animal welfare. Anim Behav 1988;36:1696707.

[30] Hutt C, Hutt SJ. Effects of environmental complexity on stereotyped behaviours of children. Anim Behav 1965;13:1-4.

[31] Jones GH, Marsden CA, Robbins TW. Behavioural rigidity and rule-learning deficits following isolation-rearing in the rat-neurochemical correlates. Behav Brain Res 1991;43:35-50.

[32] Joyce EM, Iversen SD. Dissociable effects of 6-OHDA-induced lesions of neostriatum on anorexia, locomotor-activity and stereotypy - the role of behavioural competition. Psychopharmacology 1984;83:363-6.

[33] Kennes D, Ödberg FO, Bouquet Y, Derycke PH. Changes in naloxone and haloperidol effects during the development of captivity-induced jumping stereotypy in bank voles. Eur J Pharmacol 1988;153:19-24.

[34] Kersten AMP, Behaviour and welfare of chinchillas in commericial farming: A preliminary study. In: Proc. 31st International Congress of the International Society for Applied Ethology. Hemsworth PH, Spinka M, Kostal L, editors. The International Society for Applied Ethology, Prague, Czech Republic: 1997, p. 171. 
[35] Kostal L, Savory CJ. Behavioural responses of restricted-fed fowls to pharmacological manipulation of 5-HT and GABA receptor subtypes. Pharmacol Biochem Behav 1996;53:995-1004.

[36] Lewis MH, Gluck JP, Beauchamp AJ, Keresztury MF. Longterm effects of early social isolation in Macaca mulatta: changes in dopamine receptor function following apomorphine challenge. Brain Res 1990;513:67-73.

[37] Lewis MH, Gluck JP, Bodfish JW, Beauchamp AJ. Neurobiological basis of stereotyped movement disorder. In: Sprague RL, Newell KM, et al, editors. Stereotyped movements: brain and behaviour relationships. Washington, DC, USA: American Psychological Association, 1996:37-67.

[38] Longoni R, Spina L, Mulas A, Carboni E, Garau L, Melchiorri P, Di Chiara G. (D-Ala2)deltorphin II: D1-dependent stereotypies and stimulation of dopamine release in the nucleus accumbens. $\mathbf{J}$ Neurosci 1991;11:1565-76.

[39] Luria AR. Two kinds of motor perseveration in massive injury of the frontal lobes. Brain 1965;88:1-11.

[40] Lyon M, Robbins T. The action of central nervous system stimulant drugs: a general theory concerning amphetamine effects. Curr Dev Psychopharmacol 1975;2:79-163.

[41] Manschreck TC, Maher BA, Ader DN. Formal thought disorder, the type-token ratio, and disturbed voluntary motor movement in schizophrenia. Br J Psychiatry 1981;139:7-15.

[42] Martin LJ, Spicer DM, Lewis MH, Gluck JP, Cork LC. Social deprivation of infant rhesus monkeys alters the chemoarchitecture of the brain: I. Subcortical regions. J Neurosci 1991;11:3344-58.

[43] Mason G. Early weaning enhances the later development of stereotypy in mink. In: Duncan I, Widowski T, Haley D, editors. Proceedings of the 30th International Congress of the ISAE. The International Society for Applied Ethology, Guelph, Canada, 1996. p. 16.

[44] Mason GJ. Stereotypies and suffering. Behav Proc 1991;25:10315.

[45] Mason GJ. Stereotypies: a critical review. Anim Behav 1991;41:1015-37.

[46] Mason GJ, Leipoldt A, de Jonge G. Why do female mink with high stereotypy levels have slow-growing offspring? In: Rutter SM, Rushen J, Randle HD, Eddison JC, editors. Proceedings of the 29th international congress of the international society for applied ethology. The International Society for Applied Ethology, Exeter, UK, 1995. p. 133-4.

[47] Meyer-Holzapfel M. Abnormal behaviour in zoo animals. In: Fox MW, editor. Abnormal behaviour in animals. London: Saunders, 1968:476-503.

[48] Morgan MJ, Einon DF, Nicholas D. The effects of isolation rearing on behavioural inhibition in the rat. Q J Exp Psychol 1975;27:615-34

[49] Nevison CM, Barnard CJ, and Hurst JL. An investigation into the motivational basis behind the development of bar related stereotypy in male ICR(CD-1) mice. In: Veissier I, Boissy A, editors. 32st International Congress of the International Society for Applied Ethology. The International Society for Applied Ethology, Clermont-Ferrand, France, 1998. p. 55.

[50] Nevison CM, Hurst JL, Barnard CJ. Strain-specific effects of cage enrichment in male laboratory mice (Mus musculus). Anim Welfare 1999;8:361-79.

[51] Nevison CM, Hurst JL, Barnard CJ. Why do male ICR(CD-1) mice perform bar-related (stereotypic) behaviour. Behav Proc 1999;47:95-111.

[52] Norman DA, Shallice T. Attention to action: willed and automatic control of behaviour. In: Davidson RJ, Schwartz GE, Shapiro D, editors. Consciousness and self-regulation: advances in research and theory, vol. 4. New York: Plenum Press, 1986:118.

[53] Ödberg FO. The jumping stereotypy in the bank vole (Clethrionomys glareolus). Biol Behav 1986;11:130-43.
[54] Ödberg FO, Kennes D, Derycke PH, Bouquet Y. The effect of interference in catecholamine biosynthesis on captivity-induced jumping stereotypy in bank voles (Clethrionomys glareolus). Arch Int Pharmacodyn Ther 1987;285:34-42.

[55] Olton DS. Behavioural and neuroanatomical differentiation of response-suppression and response-shift mechanisms in the rat. J Comp Physiol Psych 1972;78:450-6.

[56] Owens DGC, Johnstone EC, Frith CD. Spontaneous involuntary disorders of movement - their prevalence, severity, and distribution in chronic-schizophrenics with and without treatment with neuroleptics. Arch Gen Psychiatry 1982;39:452-61.

[57] Poulsen EMB, Honeyman V, Valentine PA, Teskey GC. Use of fluoxetine for the treatment of stereotypical pacing behaviour in a captive polar bear. J Am Vet Med Assoc 1996;209:1470.

[58] Powell SB, Newman HA, Pendergast JF, Lewis MH. A rodent model of spontaneous stereotypy: initial characterisation of developmental, environmental, and neurobiological factors. Physiol Behav 1999;66:355-63.

[59] Robbins TW. Arousal systems and attentional processes. Biol Psychol 1997;45:57-71.

[60] Rolls ET. Neurophysiology and cognitive functions of the striatum. Rev Neurol 1994;150:648-60.

[61] Rosenzweig MR, Bennett EL, Hebert M, Morimoto H. Social grouping cannot account for cerebral effects of enriched environments. Brain Res 1978;153:563-76.

[62] Rushen J, Lawrence AB, Terlouw EMC. The motivational basis of stereotypies. In: Lawrence AB, Rushen J, editors. Stereotypic animal behaviour: fundamentals and applications to welfare. Wallingford, England, UK; Tucson, AZ, USA: CAB International, 1993:41-64

[63] Sharman DF, Mann SP, Fry JP, Banns H, Stephens DB. Cerebral dopamine metabolism and stereotyped behaviour in early-weaned piglets. Neuroscience 1982;7:1937-44.

[64] Sørensen G, Randrup A. Possible protective value of severe psychopathology against lethal effects of an unfavourable milieu. Stress Med 1986;2:103-5.

[65] Steiner H, Gerfen CR. Role of dynorphin and enkephalin in the regulation of striatal output pathways and behaviour. Exp Brain Res 1998;123:60-76.

[66] Toates F. Multiple factors controlling behaviour: implications for stress and welfare. In: Moberg GP, Mench JA, editors. The biology of animal stress: basic principles and implications for animal welfare. Wallingford, UK; New York, NY: CAB International, 2000:199-226.

[67] Turner M. Towards an executive dysfunction account of repetitive behaviour in autism. In: Russell J, et al, editor. Autism as an executive disorder. New York, NY, USA: Oxford University Press, 1997:57-100.

[68] Waddington JL, Molloy AG, O’Boyle KM, Pugh MT. Aspects of stereotyped and non-stereotyped behaviour in relation to dopamine receptor subtypes. In: Cooper SJ, Dourish CT, et al, editors. Neurobiology of stereotyped behaviour. Oxford, England UK: Clarendon Press/Oxford University Press, 1990:64-90.

[69] Wadenberg M-L. Serotonergic mechanisms in neuroleptic-induced catalepsy in the rat. Neurosci Biobehav Rev 1996;20:325-39.

[70] Wiedenmayer C. Causation of the ontogenetic development of stereotypic digging in gerbils. Anim Behav 1997;53:461-70.

[71] Wood-Gush DGM, Stolba A, Miller C. Exploration in farm animals and animal husbandry. In: Archer J, Birke LIA, editors. Exploration in animals and humans. London: Van Norstrand Rienhold, 1983:198-209.

[72] Würbel H. Behaviour and the standardisation fallacy. Nat Genet 2000;26:263.

[73] Würbel H. Ideal homes? Housing effects on rodent brain and behaviour. Trends Neurosci 2001;24:207-11. 
[74] Würbel H, Chapman R, Rutland C. Effect of feed and environmental enrichment on development of stereotypic wire-gnawing in laboratory mice. Appl Anim Behav Sci 1998;60:69-81.

[75] Würbel H, Stauffacher M. Age and weight at weaning affect corticosterone level and development of stereotypies in ICR-mice. Anim Behav 1997;53:891-900.
[76] Würbel H, Stauffacher M. Physical condition at weaning affects exploratory behaviour and stereotypy development in laboratory mice. Behav Proc 1998;43:61 -9.

[77] Würbel H, Stauffacher M, vonHolst D. Stereotypies in laboratory mice-Quantitative and qualitative description of the ontogeny of 'wire-gnawing' and 'jumping' in Zur:ICR and Zur:ICR nu. Ethology 1996;102:371-85. 